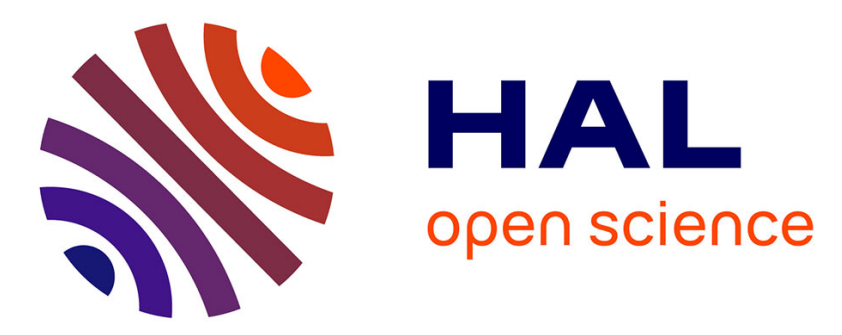

\title{
Erratum - Etudes sous champ magnétique de l'effet tunnel résonnant et non-résonnant dans les structures à double barrière n-(AlGa)As/GaAs.
}

\author{
Alain Celeste
}

\section{- To cite this version:}

Alain Celeste. Erratum - Etudes sous champ magnétique de l'effet tunnel résonnant et non-résonnant dans les structures à double barrière n-(AlGa)As/GaAs.. Revue de Physique Appliquée, 1989, 24 (8), pp.847-847. 10.1051/rphysap:01989002408084700 . jpa-00246107

\section{HAL Id: jpa-00246107 https://hal.science/jpa-00246107}

Submitted on 1 Jan 1989

HAL is a multi-disciplinary open access archive for the deposit and dissemination of scientific research documents, whether they are published or not. The documents may come from teaching and research institutions in France or abroad, or from public or private research centers.
L'archive ouverte pluridisciplinaire HAL, est destinée au dépôt et à la diffusion de documents scientifiques de niveau recherche, publiés ou non, émanant des établissements d'enseignement et de recherche français ou étrangers, des laboratoires publics ou privés. 


\section{Erratum}

Etudes sous champ magnétique de l'effet tunnel résonnant et non-résonnant dans les structures à double barrière n-(AlGa)As/GaAs.

A. Céleste et al.

(Revue Phys. Appl. 24 (1989) 343).

Suite à une erreur de la liste d'auteurs, il faut lire :

A. Céleste $\left({ }^{1}\right)$, L. Eaves $\left({ }^{2}\right)$, E. S. Alves $\left({ }^{2}\right)$, T. J. Foster $\left({ }^{2}\right)$, M. Henini $\left({ }^{2}\right)$, O. H. Hughes $\left({ }^{2}\right)$, M. L. Leadbeater $\left({ }^{2}\right)$, F. W. Sheard $\left({ }^{2}\right)$, G. A. Tombs $\left({ }^{2}\right)$, K. Chan $\left({ }^{2}\right)$, J. C. Portal $\left({ }^{1}\right)$, G. Hill $\left({ }^{3}\right)$ and M. A. Pate $\left({ }^{3}\right)$.

Ces travaux ont été présentés oralement à la $5^{\mathrm{e}}$ Ecole Internationale à Mauterndorf, 22-26 février 1988, Autriche (Springer Series in Solid State Sciences 83, Physics and technology of Submicron. Structures (1988) p. 74) et aux Journées Nationales Microélectronique III-V du CNRS à Oléron, 1-3 juin 1988 en Poster. 